\title{
Eski Türk Bengü Taşlarında Paralelizm
}

Hüseyin YILDIZ ${ }^{1}$

\author{
$\ddot{O} \mathbf{z}$
}

Dil araştırmalarının edebiyat araştırmaları ile kesiştiği konulardan biri olan stilistik (üslup bilimi) aynı zamanda tarihsel dilbilimi, sosyolengüistik, psiko-lengüistik gibi dilbiliminin alt dallarıyla da ilgilidir. Stilistiğin konularından biri olan paralelizm kısaca, benzer kelimelerin benzer ekler alarak ahenkli bir şekilde sıralanması olarak değerlendirilebilir. Eski Türkçe metinler esaslı üslup çalışmalarının sayısı fazla değildir ve bu konuda kapsamlı çalışmalar ortaya konmamıştır. Eski Türk bengü taşlarına bakıldığında üslup özelliği gösteren bazı paralelizm örneklerine rastlanmaktadır. Bir örnek olarak Köl Tigin yazıtı güney yüzü ikinci satırda geçen ilgerü kün togsık(k)a birigerü kün ortusıjaru kurıaru kün batsıkıja yırıgaru tün ortusımaru ifadeleri verilebilir. Bu ifadede sistemli olarak ekler ve kelimeler birbirine paralel bir şekilde bir araya getirilmiştir:

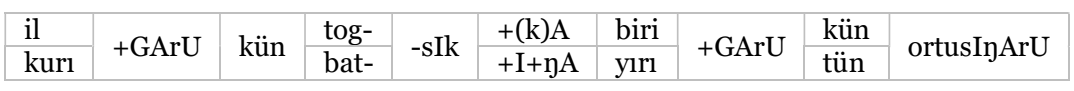

Eski Türk bengü taşlarındaki paralelizm örneklerinin ele alınacağı bu çalışmada, cümle ve kelime grubu esaslı inceleme, tespit ve değerlendirmeler yapılacak, Türk dilinin en eski metinlerinin üslubunu belirlemeye yönelik bir deneme ortaya atılacaktır.

Anahtar kelimeler: Eski Türkçe, Türk bengü taşları, paralelizm.

\section{Paralelism in Old Turkic Inscriptions}

\begin{abstract}
Stylistic is one of the common subjects of literature and language researches. Also, it is related to the subsections of linguistics such as historical linguistics, sociolinguistic, psycholenguistic. Parallelism is one of the research issues of the stylisyics. Parallelism is a stylistic sign and can only be effectively explored in a linguistic stylistic study. Basically, paralellism can be regarded as harmonious manner sequencing of similar words by adding similar suffixes. The number of stylistic studies on Old Turkic runic inscriptions are not more and comprehensive studies on this subject have not been done yet. When we look at the old Turkic runic inscriptions, there are seen some examples of parallelism showing stylistic features. As an example, can be given the following phrases written on the second line of the southern front of the Köl Tigin inscription: ilgerü kün togsık(k)a birigerü kün ortusıaru kurıaru kün batsıkına yırıgaru tün ortusıjaru. In these phrases, systematically, the words and suffixes are used together in parallel.
\end{abstract}

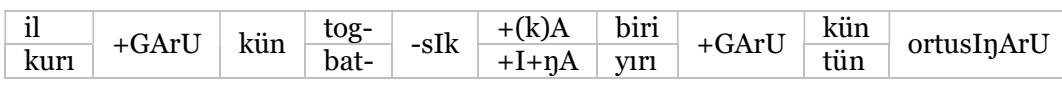

Dr. Öğr. Üye., Ordu Üniversitesi, Fen Edebiyat Fakültesi, Türk Dili ve Edebiyatı Bölümü, turkbilimci@gmail.com [Makale kayt tarihi: 30.6.2018-kabul tarihi: 15.8.2018] 
In this study, firstly the examples of paralelism in Old Turkic inscriptions were examined. Then sentence and vocabulary group based reviews, findings and evaluations were made. Thus, an attempt be made to determine the style of the oldest texts of the Turkic languages.

Key words: Old Turkic, Turkic Runic inscriptions, parallelism.

\section{Giriş}

Türk dilinin en eski yazılı ürünleri sayılan bengü taşlar, dilbiliminin fonetik, fonoloji, semantik, sentaks gibi dallarındaki akademik çalışmalara sık sık kaynaklık etse de, stilistik ve edebiyat çalışmalarında aynı slklığa rastlanmaz. Bu sebeple bengü taşlardaki üslûp, edebî sanatlar, anlatım tarzları gibi konular hakkındaki çalışmalar (Korş 1906; Stebleva 1963, 1965, 1969, 1976, 1991; Bombaci 1965; Jirmunsky 1968; Hrebiček 1969; Tekin 1986; Ercilasun 1990; Bayat 2004, 2006; Hacıyev 2011 vd.) oldukça sinirlıdır.

Eski Türk bengü taşlarındaki paralelizm örnekleri bu çalışmanın konusudur, ancak bu örneklerin ilk kez bu çalışmada konu edilmediğini belirtmek gerekir. Korş’un 1906'da yayınlanan eserinde, Stebleva'nın ise 1960'lı yıllardan itibaren yayınladığı pek çok çalışmasında bu örneklerin bir kısmı bengü taşların anlatım tarzının manzum olduğunu ispatlamaya yönelik olarak kullanılmıştır. Aynı örneklerden yola çıarak Jirmunsky (1968), Hrebiček (1969), Tekin (1986) vb. bilim adamları bu görüşe karşı çıkmışlardır. Ercilasun (1990)'da bir kısım paralelizm örnekleri, bengü taşların bir nutuk metni olabileceğini düşündürmek için kullanılmıştır. Bu çalışmada, Köl Tigin, Bilge Kağan, Tonyukuk I-II bengü taşlarındaki paralelizm örneklerinin tamamı tespit edilerek, bu örnekler üzerinden önceki çalışmalarda hiç ya da yeterince bahsedilmeyen hususlar üzerinden değerlendirmeler yapılacaktır.

\section{Paralelizm Örnekleri ve Bengü Taşlar}

Daha çok felsefe, halkbilimi ve eğitim bilimlerinde koşutçuluk $k^{2}$ karşılığında kullanılan paralelizm (İng. parallelism), edebiyat incelemelerinde, özellikle de şiir dilinde dizeler arasında şekil bakımından bir uyumun olması durumu olup "şiir dilinde beyti oluşturan mısralar arasındaki benzer dil birliklerinin ve mütevazin kelimelerin anlamla bütünleşen sesin eşliğinde paralel sıralanışını ifade eden bir terim (Macit 1996: 59)" şeklinde tanımlanır. Edebî sanatlar arasında tarsi veya murassa terimleriyle ilgili olarak ise Dilçin'de şu bilgiler verilmektedir (1991: 86):

Divan şiirinde, dizelerdeki sözcükleri ölçü ve uyak bakımından birbirine denk getirme (mütevâzin ve mukaffâ) tarsî sanatıdır. Dizelerdeki sözcükler sayı bakımından da birbirine eşit olmak zorundadır. Dizeleri yapı bakımından böyle simetrik ve paralel (mütenâzır ve mütevâzî) olan beyit ve şiirlere murassa‘ denir. Bu denklik sadece sözcüklerde değil tamlamalar ve Türkçe eklerde de aranır.

Türk dilinde paralelizm örnekleri üzerine çeşitli metinler esasında bazı çalışmalar (Dilçin 1991, 2000; Macit 1996; Musaoğlu 2003; Aslan 2010, Gül 2013) yapılmıştır.

Kişide, ruhsal ve bedensel olaylar arasında koşutluk bulunduğunu ileri süren öğreti, paralelizm (GTS); Birbirleriyle hiçbir ilişki ve değinileri olmayan halk kültürlerinde benzer halkbilim ürün ve olaylarının gelişimi ya da tüm halk kültürlerinde varlığı ileri sürülen doğrusal evrim. bk. koşut gelişim. krş. yayılım, temel düşünce, dağılım (BSTS/H); Zihin ile bedenin aynı zamanda görev yapmalarına karşın aralarında herhangi bir iliş̧i bulunmayan iki ayrı varlık olduğunu, ruhsal olaylar ile bedensel olayların birbirini hiç etkilemeyen karşıllılı iki dizi biçiminde oluştuğunu ileri süren öğreti (BSTS/E). 
Bu çalışmanın veri tabanını oluşturan Köl Tigin, Bilge Kağan ve Tonyukuk I-II bengü taşlarındaki paralelizm örnekleri tarandığında, toplamda 68 veriyle karşılaşılmaktadır.

\subsection{Eklerin ve Kelimelerin Dağılımı ${ }^{3}$}

Köl Tigin, Bilge Kağan ve Tonyukuk I-II bengü taşlarındaki 68 paralelizm örneğinin üç şekilde paralellik oluşturduğu görülmektedir. Buna göre bengü taşlarda sadece kelimelerden oluşan 8 , sadece eklerden oluşan 14, ek ve kelimelerden karma olarak oluşan 46 paralelizm örneğine rastlanmaktadır.

\subsubsection{Sadece Kelimelerden Oluşan Paralelizm Örnekleri}

Bengü taşlarda sadece kelimelerden oluşan 8 paralelizm örneği, kelime sayısına bağlı olarak beş alt grupta değerlendirilebilir.

\section{$\mathbf{K 5}$}

BG/2: otuz artukı sekiz yaşıma kışın kıtań tapa süledim (otuz artukı tokuz ya)şıma yazın tatabı tapa sü(ledim...)

\begin{tabular}{|c|c|c|c|c|c|}
\hline \multirow{2}{*}{ otuz artukl } & sekiz & \multirow{2}{*}{ yaşıma } & kışın & kutań & \multirow{2}{*}{ tapa süledim } \\
\hline & tokuz & & yazm & tatabl & \\
\hline
\end{tabular}

\section{K4}

BG/9: tokuz yigirmi yıl şad olurtum toku(z yigir)mi yıl kagan olurtum

tokuz yigirmi yal

\begin{tabular}{|c|c|}
\hline şad & olurtum \\
\hline kagan & \\
\hline
\end{tabular}

T-IID/4: ilteriş kagan kazganmasar udu ben özüm kazganmasar; T-IIK/1: ilteriş kagan kazganmasar yok erti erser ben özüm bilge tuńukuk kazganmasar ben yok ertim erser

\begin{tabular}{|c|c|c|c|c|c|c|c|}
\hline \multirow{2}{*}{ T-IID/4 } & ilteriş kagan & \multirow{4}{*}{ kazganmasar } & \multicolumn{5}{|c|}{-} \\
\hline & udu ben özüm & & \multicolumn{5}{|c|}{-} \\
\hline \multirow{2}{*}{ T-IIK/1 } & ilteriş kagan & & - & \multirow{2}{*}{ yok } & \multirow{2}{*}{ erti } & - & \multirow{2}{*}{ erser } \\
\hline & ben özüm bilge tuńukuk & & ben & & & $-m$ & \\
\hline
\end{tabular}
kelimeleri karşılamaktadır. Simgelerin yanında belirtilen sayılar, ek ya da kelimenin ilgili paralelizm örneğinde kaç defa geçtiğini göstermeye yöneliktir. Sözgelimi $\mathrm{E}_{5}+\mathrm{K} 2$ simgesi, o örnekte beş ekte ve iki kelimede paralelizm bulunduğunu ifade etmektedir. 
96 / RumeliDE Journal of Language and Literature Studies 2018. Special Issue 4 (August)

Paralelism in Old Turkic Inscriptions / H. Ylldız (p. 93-122)

\section{K3}

KD/5: biligsiz kagan olurmış erinç yablak kagan olurmış erinç; $\mathrm{BD} / 6$ : biligsiz kagan olurmış erinç yablak kagan olurmış erinç

\begin{tabular}{|l|l|}
\hline biligsiz & \multirow{2}{*}{ kagan olurmış erinç } \\
\hline yablak & \\
\hline
\end{tabular}

KG/7: trak erser yablak agı birür yaguk erser edgü agı birür; BK/5: ırak erser yablak agı birür yaguk erser edgü agı birür

\begin{tabular}{|c|c|c|c|}
\hline trak & \multirow{2}{*}{ erser } & yablak & agı birür \\
\hline yaguk & & edgü & \\
\hline
\end{tabular}

\section{K2}

T-IB/4: iki ülügi atlhg erti bir ülügi yadag erti

\begin{tabular}{|c|c|c|c|}
\hline$i k i$ & \multirow{2}{*}{ ülügi } & athg & \multirow{2}{*}{ erti } \\
\hline bir & & yadag & \\
\hline
\end{tabular}

T-IID/6: il yeme il bolt bodun yeme bodun boltı

\begin{tabular}{|c|c|c|c|}
\hline il & yeme & il & boltz \\
\hline bodun & yeme & bodun \\
\hline
\end{tabular}

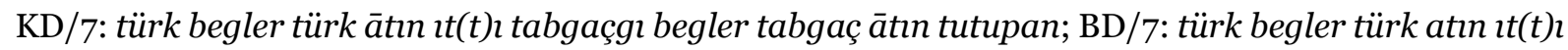
tabga[çgı] begler tabga[çàtın tutupan

\begin{tabular}{|c|c|c|c|c|}
\hline türk & \multirow{2}{*}{ begler } & türk & \multirow{2}{*}{$\bar{a} t ı n$} & $\imath t(t) \imath$ \\
\hline tabgaçgı & & tabgaç & & tutupan \\
\hline
\end{tabular}

\section{K1}

$\mathrm{KD} / 1$ : tuta birmiş iti birmiş; $\mathrm{BD} / 3$ : tuta birmiş iti birmiş

\begin{tabular}{|c|c|}
\hline tut- $a$ & birmiş \\
\hline$i t-i$ & \\
\hline
\end{tabular}

\footnotetext{
Adres | Adress 


\subsubsection{Sadece Eklerden Oluşan Paralelizm Örnekleri}

Bengü taşlarda sadece eklerden oluşan 14 paralelizm örneği, ek sayısına bağlı olarak beş alt grupta değerlendirilebilir.

\section{E5}

T-IID/4: yarakhg yagıg yeltürmedim tügünlüg atıg yügürtmedim

\begin{tabular}{|c|c|c|c|c|c|}
\hline yarak & \multirow{4}{*}{+ lIg } & yagı & & yeltür- & -mA-dI-m \\
\hline tügün & & at & $+(I) g$ & yügürt- & \\
\hline
\end{tabular}

\section{E4}

$\mathrm{KD} / 15$ : illigig ilsiretmiş kaganlıgıg kagansıratmış yagıg baz kılmış; $\mathrm{KD} / 18$ : illigig ilsiretdimiz kaganlıgıg kagansıratdımız; BD/13: illigig ilsiretmiş kaganlıgıg kagansıratmış yagıg baz kılmış; $\mathrm{BD} / 15$ : [illigig ilsiretdimiz kaganlıgı kagansiratdımız]

\begin{tabular}{|c|c|c|c|c|c|}
\hline$i l$ & \multirow{2}{*}{$+l I g$} & \multirow{3}{*}{$+(I) g$} & $i l$ & & \multirow{3}{*}{$-m I s$} \\
\hline kagan & & & kagan & & \\
\hline yag & - & & $b a z$ & kul- & \\
\hline
\end{tabular}

BK/11: közün körmedük kulkakın eşidmedük

\begin{tabular}{|c|c|c|c|}
\hline$k$ köz & \multirow{2}{*}{$+I+n$} & kör- & \multirow{2}{*}{$-m A-d U k$} \\
\cline { 1 - 3 } kulkak & & eşid- & \\
\hline
\end{tabular}

\section{E3}

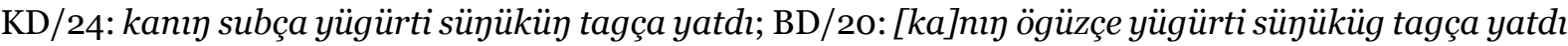

\begin{tabular}{|c|c|c|c|c|c|}
\hline kan & \multirow{2}{*}{$+(I) \eta$} & $s u b$ & \multirow{2}{*}{$+c ̧ A$} & yügür- & \multirow{2}{*}{$-D I$} \\
\hline sǖük & & tag & & yat- & \\
\hline
\end{tabular}

$\mathrm{KD} / 2$ : başlıgıg yüküntürmiş tizligig sökürmiş; $\mathrm{KD} / 15$ : tizligig sökürmiş başlıgıg yüküntürmiş; $\mathrm{KD} / 18$ : tizligig sökürtümüz başhgıg yüküntürtümüz; BK/10: b)aş(l)ıgıg yüküntürtüm tizligig sökürtüm; BD/3: başhgııg yüküntürmiş tizlig[ig sökürmiş; $\mathrm{BD} / 13$ : tizligig sökürmiş başhgıg yüküntürmiş; $\mathrm{BD} / 15^{-}$ 16: tizligig] sökürtümüz başhgıg yüküntürtümüz

\begin{tabular}{|l|c|c|c|c|}
\hline \multirow{2}{*}{$\mathrm{KD} / 2$} & baş & \multirow{2}{*}{$+\operatorname{sg}+I g$} & yüküntür- & -miş \\
\cline { 2 - 2 } $\mathrm{KD} / 15$ & tiz & & sökür- & \\
\hline
\end{tabular}




\begin{tabular}{|c|c|c|c|c|}
\hline $\begin{array}{l}\mathrm{BD} / 3 \\
\mathrm{BD} / 13\end{array}$ & & & & \\
\hline $\mathrm{KD} / 18$ & baş & yüküntür- & \multirow{4}{*}{$-t \ddot{u}$} & \multirow[t]{2}{*}{-müz } \\
\hline $\mathrm{BD} / 15^{-16}$ & tiz & sökür- & & \\
\hline \multirow{2}{*}{$\mathrm{BK} / 10$} & baş & yüküntür- & & \multirow[t]{2}{*}{$-m$} \\
\hline & tiz & sökür- & & \\
\hline
\end{tabular}

E2

T-IG/14: öyre kıtańda biriye tabgaçda kurıya kordanta yırıya oguzda

\begin{tabular}{|c|c|c|c|}
\hline$\ddot{o} \eta$ & $+r A$ & kutań & \multirow{4}{*}{$+D A$} \\
\hline biri & \multirow{3}{*}{$+(y) A$} & tabgaç & \\
\hline kurl & & kordan & \\
\hline yirl & & oguz & \\
\hline
\end{tabular}

KD/11: kayım iltiriş kaganıg ögüm ilbilge katunug; KD/25: kayım kaganıg ögüm katunug; $\mathrm{BD} / 10$ : kayım iltiriş kaganı ögüm ilbilge katunug; BD/20-21: kayım kaganı ögüm katunug

\begin{tabular}{|c|c|c|c|c|}
\hline \multirow{2}{*}{ kay } & \multirow{3}{*}{$+(I) m$} & iltiriş & kagan & \multirow{2}{*}{$+(I) g$} \\
\cline { 1 - 2 } & \multirow{2}{*}{$g$} & ilbilge & katun & \\
\hline
\end{tabular}

KD/12: balıkdakı tagıkmış tagdakı inmiş; BD/10-11: ba]l[ık]da[kı taşıkmış tagdakı] inmiş

\begin{tabular}{|c|c|c|c|c|}
\hline \multirow{2}{*}{$\mathrm{KD} / 12$} & ballk & \multirow{4}{*}{$+D A+k I$} & tagık- & \multirow{4}{*}{$-m I s ̧$} \\
\hline & $\operatorname{tag}$ & & in- & \\
\hline \multirow{2}{*}{$\mathrm{BD} / 10-11$} & ballk & & taşık- & \\
\hline & $\operatorname{tag}$ & & in- & \\
\hline
\end{tabular}

$\mathrm{KD}$ /26: içre aşsız taşra tonsuz; $\mathrm{BD} / 21$ : içre aşsız taşra tonsuz

\begin{tabular}{|c|c|c|c|}
\hline iç & \multirow{3}{*}{$+r A$} & aş & \multirow{2}{*}{+ sIz } \\
\cline { 1 - 3 } & taş & ton & \\
\hline
\end{tabular}

BD/37: içikigme içikdi bodun boltı ölügme ölti

\begin{tabular}{|l|l|l|l|}
\hline içik- & $-(I) g m A$ & $i c ̧ i k-$ & $-D I$ \\
\hline
\end{tabular}




\begin{tabular}{|c|c|c|}
\hline bodun & - & bol- \\
\hline öl- & $-(I) g m A$ & öl- \\
\hline
\end{tabular}

T-IID/2: kızıl kanım töküti kara terim yügürti

\begin{tabular}{|c|c|c|c|c|}
\hline kızul & kan & \multirow{2}{*}{$+(I) m$} & tökü- & \multirow{2}{*}{$-D I$} \\
\hline kara & ter & & yügür- & \\
\hline
\end{tabular}

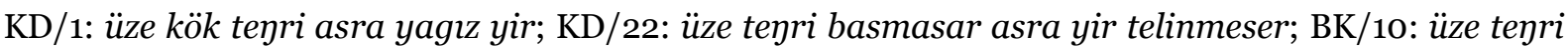
asra yir; $\mathrm{BD} / 2$ : üze kök teyri asra yagız yir; $\mathrm{BD} / 18$ : üze tepri basma[sar asra] yir telinmeser

\begin{tabular}{|c|c|c|c|c|c|}
\hline \multirow{2}{*}{$\begin{array}{l}\mathrm{KD} / 1 \\
\mathrm{BD} / 2\end{array}$} & üze & $k o ̈ k$ & tegri & \multirow{2}{*}{\multicolumn{2}{|c|}{-}} \\
\hline & asra & yagız & yir & & \\
\hline \multirow{2}{*}{$\begin{array}{l}\mathrm{KD} / 22 \\
\mathrm{BD} / 18\end{array}$} & üze & \multirow{4}{*}{-} & tegri & bas- & \multirow{2}{*}{$-m A-s A r$} \\
\hline & asra & & yir & telin- & \\
\hline \multirow{2}{*}{$\mathrm{BK} / 1 \mathrm{O}$} & üze & & teyri & \multirow{2}{*}{\multicolumn{2}{|c|}{-}} \\
\hline & asra & & yir & & \\
\hline
\end{tabular}

KD/27: tün udımadım küntüz olurmadı[m]; BD/22: tün udımadım küntüz olurmadım; T-ID/5: tün yeme udısıkım kelmez erti (kün yeme) olursıkım kelmez erti; T-IID/2: tün udımatı küntüz olurmatı

\begin{tabular}{|c|c|c|c|}
\hline tün & yeme & udt- & -sIk+Im kelmez erti \\
\hline küntüz & olur- & -mAtI \\
\hline tün & udl- & \\
\hline küntüz & - & olur- & -mA-dI-m \\
\hline tün & & udt- & \\
\hline küntüz & & olur- & \\
\hline
\end{tabular}

\subsubsection{Ekler ve Kelimelerden Oluşan Karma Paralelizm Örnekleri}

Bengü taşlarda ek ve kelimelerden karma olarak oluşan 46 paralelizm örneği, ek ve kelime sayısına bağlı olarak 18 alt grupta değerlendirilebilir.

\section{$\mathbf{E}_{7+\mathrm{K1}}$}

KD/6: begleri bodun tüzsüz üçün tabgaç bodun tebligin kürlüg üçün armakçısın üçün inili eçili kikşürtükin üçün begli bodunlgg yoyaşurtukın üçün; BD/6-7: begleri bodunı tüzsüz üçün tabgaç bodun 
tebli[gin] kürlügin [üçün armakçı]sın üçün inili [eçili kikşürtükin üçün begli bodunlıg] yojaşurtukın üçün

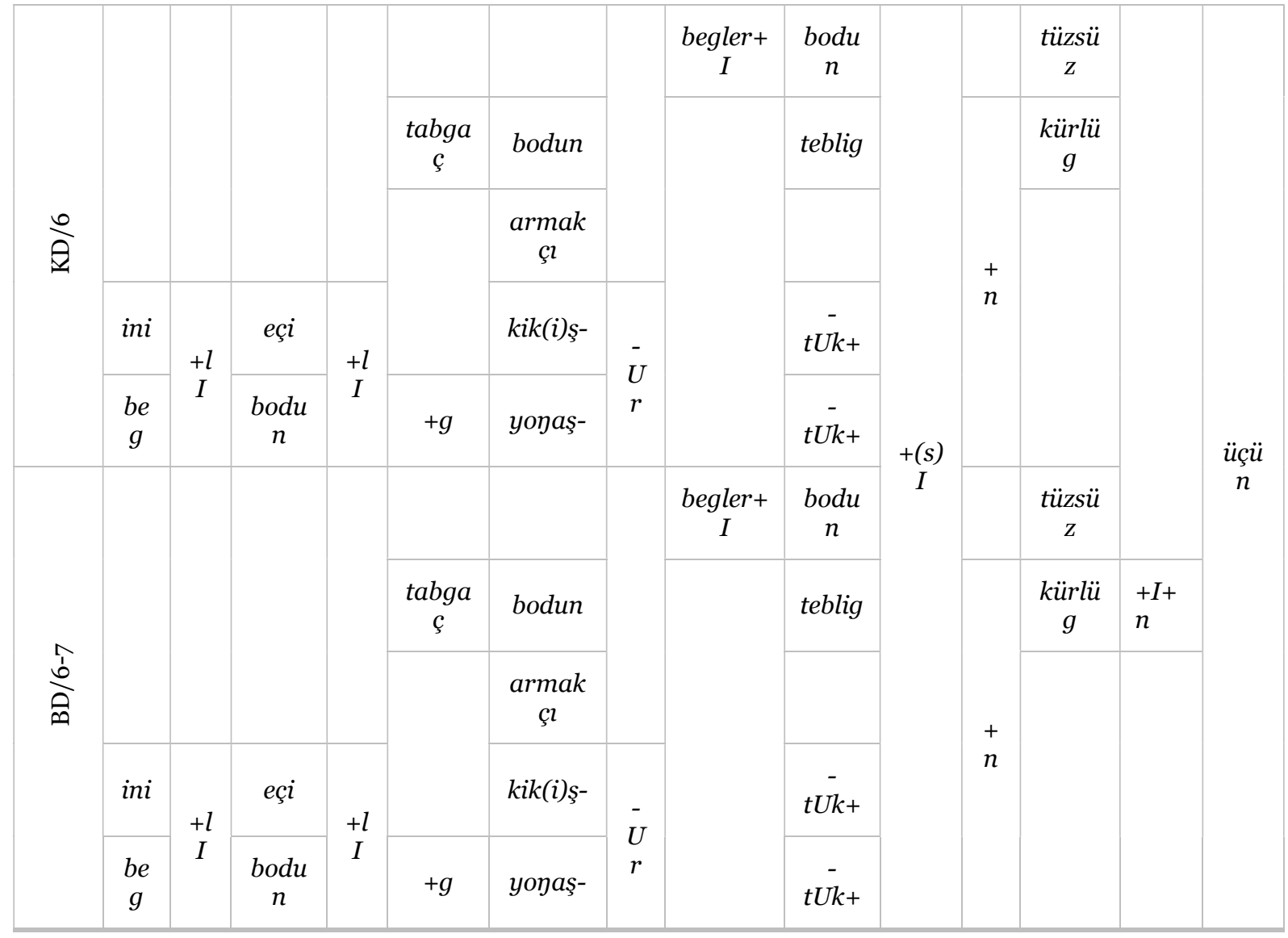

\section{$\mathbf{E}_{5}+\mathrm{K}_{5}$}

KD/9: illig bodun ertim ilim amtı kanı kimke ilig kazganur men tir ermiş kaganlıg bodun ertim kaganım kanı ne kaganka işig küçüg birür men tir ermiş; BD/8-9: illig bodun [ertim ilim amtı kanı kimke ilig kazganur men tir ermiş] kaganhg bodun ertim kaganım kanı ne kaganka işig küçüg birür men tir ermiş

\begin{tabular}{|c|c|c|c|c|c|c|c|c|c|c|c|}
\hline il & \multirow{2}{*}{$\begin{array}{l}+ \text { lIg } \\
\text { bodun } \\
\text { ertim }\end{array}$} & il & \multirow{2}{*}{$+(I) m$} & amts & \multirow{2}{*}{ kanı } & kim & \multirow{2}{*}{$+G A$} & il & \multirow{2}{*}{$+(I) g$} & kazgan- & \multirow{2}{*}{$\begin{array}{l}-(I) r \text { men } \\
\text { tir ermiş }\end{array}$} \\
\hline kagan & & kagan & & - & & $\begin{array}{c}n e \\
\text { kagan }\end{array}$ & & $\begin{array}{c}\text { iş... } \\
k \text { küç... }\end{array}$ & & bir- & \\
\hline
\end{tabular}

\section{$\mathbf{E}_{5}+\mathrm{K} 2$}

KG/2: ilgerü kün togsık(k)a birigerü kün ortusinaru kurıgaru kün batsıkıpa yırıgaru tün ortusinaru;

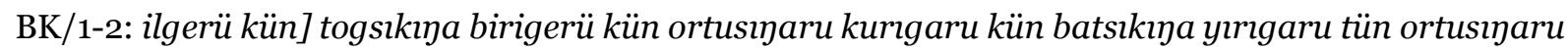

\begin{tabular}{|l|l|l|l|l|l|l|l|l|l|l|}
\hline $\mathrm{KG} / 2$ & il & $+G A r U$ & kün & tog- & $-s I k$ & $-(k) A$ & biri & + GArU & kün & ortusInArU \\
\hline
\end{tabular}




\begin{tabular}{|c|c|c|c|c|c|}
\hline & kurl & bat- & \multirow{3}{*}{$+I+\eta A$} & yirt & tün \\
\hline \multirow{2}{*}{$\mathrm{BK} / 1-2$} & $i l$ & tog- & & biri & kün \\
\hline & kurl & bat- & & yirt & tün \\
\hline
\end{tabular}

\section{$\mathbf{E} 4+\mathrm{K} 1$}

KD/6-7: illedük ilin ıçgınu ıdmış kaganladuk kaganın yitürü ıdmış; BD/7: il(l)edük ilin ıçgınu ıdmış kaganladuk kaganın yitürü ıdmış

\begin{tabular}{|c|c|c|c|c|c|}
\hline$i l$ & \multirow{2}{*}{$+l A-d U k$} & $i l$ & \multirow{2}{*}{$+I+n$} & ıçgun- & \multirow{2}{*}{$-U \imath d m \imath s ̧$} \\
\hline kagan & & kagan & & yitür- & \\
\hline
\end{tabular}

\section{E3+K6}

KD/35: köl tigin bayırkun(uy ak adgırıg) binip oplayu tegdi; KD/37: köl tigin başgu boz at binip tegdi; KK/2: alp şalçı akın binip oplayu tegdi; KK/3-4: köl tigin alp şalçı akın binip (oplayu tegd)i; KK/5: köl tigin azman akıg binip oplayu tegdi; KK/5: köl tigin az yagızn binip oplayu tegip; KK/6: köl tigin azman akın binip tegdi; KK/7-8: köl tigin az yagızın binip tegdi; KK/8-9: köl tigin ögsüz akın binip

\begin{tabular}{|c|c|c|c|c|c|c|c|c|c|}
\hline $\mathrm{KK} / 5$ & \multirow{2}{*}{ köl tigin } & \multirow{2}{*}{$a z$} & \multirow{2}{*}{ yagız } & \multirow{6}{*}{$+I$} & \multirow{6}{*}{$+n$} & \multirow{4}{*}{\multicolumn{2}{|c|}{ oplayu }} & \multirow{4}{*}{ teg- } & $-(I) p$ \\
\hline $\mathrm{KK} / 7-8$ & & & & & & & & & \\
\hline $\mathrm{KK} / 2$ & - & \multirow{2}{*}{ alp şalçı } & \multirow{5}{*}{$a k$} & & & & & & $-D I$ \\
\hline $\mathrm{KK} / 3-4$ & \multirow{6}{*}{ köl tigin } & & & & & & & & \\
\hline KK/8-9 & & ögsüz & & & & \multirow[t]{5}{*}{ binip } & - & - & - \\
\hline $\mathrm{KK} / 6$ & & & & & & & - & \multirow{4}{*}{ teg- } & \multirow{4}{*}{$-D I$} \\
\hline $\mathrm{KK} / 5$ & & & & \multirow{3}{*}{ - } & \multirow{2}{*}{$+(I) g$} & & \multirow{2}{*}{ oplayu } & & \\
\hline $\mathrm{KD} / 35$ & & bayırkunuy & ak adgr & & & & & & \\
\hline $\mathrm{KD} / 37$ & & başgu & boz at & & - & & - & & \\
\hline
\end{tabular}

\section{$\mathbf{E}_{3}+\mathrm{K} 4$}

KG/3-4: ilgerü şantū yazıka tegi süledim taluyka kiçig tegmedim birigerü tokuz ersinke tegi süledim töpütke kiçig tegmedim kurıgaru yinçü ögüz keçe temir kapıgka tegi süledim yırıaru yir bayırku yirine tegi süledim; BK/2-3: ilge[rü ş]antuך [yazıka tegi süledim taluyka kiçig tegmedim b]irigerü t[okuz] ersinke tegi süledim töpütke kiçig tegmedim kurıaru yinçü ögüz keçe temir kaprgka tegi süledim yırıgaru yir bayırku yirine tegi süle[dim]

\begin{tabular}{|l|l|l|l|l|l|l|}
\hline il & $+G A r U$ & - & şantuy yazı & $+k A$ & & taluy \\
\hline
\end{tabular}


102 / RumeliDE Journal of Language and Literature Studies 2018. Special Issue 4 (August)

Paralelism in Old Turkic Inscriptions / H. Ylldı (p. 93-122)

\begin{tabular}{|c|c|c|c|c|c|c|}
\hline biri & & tokuz ersin & & \multirow{3}{*}{$\begin{array}{c}\text { tegi } \\
\text { süledim }\end{array}$} & töpüt & $\begin{array}{l}+k A \text { kiçig } \\
\text { tegmedim }\end{array}$ \\
\hline kurl & yinçü ögüz keçe & temir kapıg & & & & \multirow{2}{*}{-} \\
\hline yir & - & yir bayırku yir & $+I+\eta A$ & & & \\
\hline
\end{tabular}

\section{$\mathbf{E} 3+\mathbf{K 1}$}

KK/10: körür közüm körmez teg bilir biligim bilmez teg

\begin{tabular}{|c|c|c|c|c|c|}
\hline kör- & & köz & & kör- & \\
\hline bil- & $-(I) r$ & bilig & $+(I) m$ & bil- & -mAz teg \\
\hline
\end{tabular}

\section{E2+K6}

KG/6: edgü bilge kişig edgü alp kişig; $\mathrm{BK} / 4$ : edgü [bil]ge kişig edgü alp kişig; KD/3: bilge kagan ermiş alp kagan ermiş; $\mathrm{BD} / 4$ : bilge kagan ermiş alp kagan ermiş; $\mathrm{KD} / 3$ : bilge ermiş erinç alp ermiş erinç; $\mathrm{BD} / 4$ : bilge ermiş erinç alp ermiş erinç; T-ID/4: kaganı alp ermiş ayguçısı bilge ermiş; $\mathrm{T}-\mathrm{IK} / 5$ : kaganı alp ermiş ayguçısı bilge ermiş; T-IIG/4-5: bilgesin üçün alpın üçün

\begin{tabular}{|c|c|c|c|c|c|c|c|}
\hline \multirow{2}{*}{$\mathrm{KG} / 6$} & \multirow{2}{*}{ edgü } & & & bilge & \multirow{2}{*}{ kişig } & \multirow{2}{*}{ - } & \\
\hline & & & & alp & & & \\
\hline \multirow{2}{*}{ T-IIG/4-5 } & & & & bilge & \multirow{2}{*}{$+(s) I+n$} & \multirow{2}{*}{ üçün } & \\
\hline & & & & alp & & & \\
\hline \multirow{2}{*}{$\mathrm{KD} / 3$} & & & & bilge & \multirow{2}{*}{ kagan } & \multirow{6}{*}{ ermiş } & \\
\hline & & & & alp & & & \\
\hline \multirow{2}{*}{$\mathrm{KD} / 3$} & & & & bilge & & & \\
\hline & & & & alp & & & वाtदु \\
\hline \multirow{2}{*}{$\mathrm{T}-\mathrm{ID} / 4$} & & kagan & \multirow{2}{*}{$+(s) I$} & $a l p$ & & & \\
\hline & & ayguçı & & bilge & & & . \\
\hline
\end{tabular}

\section{$\mathbf{E 2}+\mathrm{K}_{5}$}

$\mathrm{KD}$ /8: ilgerü kün togsıkda bük ili kaganka tegi süleyü birmiş kurıgaru temir kapıgka tegi süleyü birmiş; $\mathrm{BD} / 8$ : ilgerü kün togsık(k)a bük ili kaganka tegi süleyü birmiş kurıaru temir kapıgka tegi süleyü birmiş

\begin{tabular}{|l|l|l|l|l|l|l|l|}
\hline $\mathrm{KD} / 8$ & il & + GArU & kün tog- & - sIk & $+D A$ & bükilikagan & \\
\hline
\end{tabular}




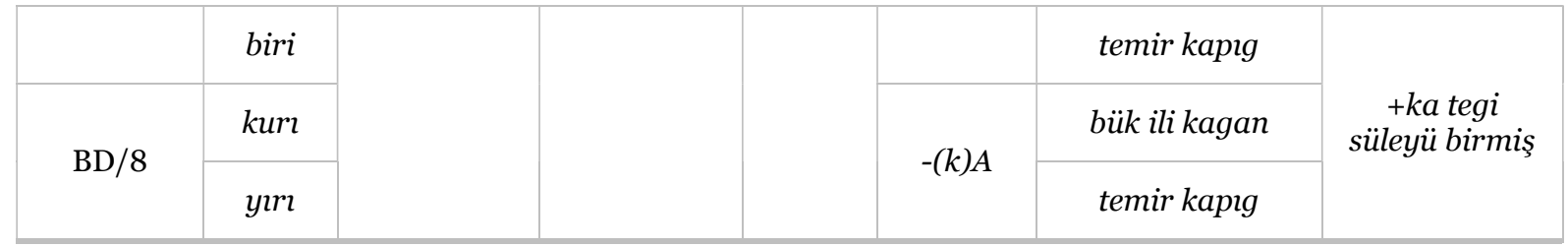

\section{E2+K4}

T-IIG/5-6: ayguçı(sı) yeme ben ök ertim yagıçısı yeme ben ök ertim

\begin{tabular}{|c|c|}
\hline aygu & \\
\cline { 1 - 2 }$y$ yagı & $+c ̧ I+(s)$ I yeme ben ök ertim \\
\hline
\end{tabular}

KG/5: sabı süçig agısı yımşak; BK/4: sabı süçig agısı yımşak; KG/5: süçig sabın yımşak agın; BK/4: süçig sabın yımşak agın; KG/6: süçig sabına yımşak agısına; BK/5: süçig sabına yımşak agısına

\begin{tabular}{|c|c|c|c|c|c|c|}
\hline $\mathrm{KG} / 5-\mathrm{BK} / 4$ & & $+n$ & & - & $+n$ & \\
\cline { 1 - 3 } $\mathrm{KG} / 5-\mathrm{BK} / 4$ & \multirow{3}{*}{ sab+I+ } & - & süçig agı & & - & yımşak \\
\hline $\mathrm{KG} / 6-\mathrm{BK} / 5$ & & $+\eta A$ & & $+(s) I$ & $+\eta A$ & \\
\hline
\end{tabular}

\section{$\mathbf{E} 2+K_{3}$}

$\mathrm{KD} / 5$ : inisi eçisin teg kulnmaduk erinç oglı kayın teg kulınmaduk erinç; $\mathrm{BD} / 5-6$ : inisi eçisin teg kılınmaduk erinç oglı kayın teg kılınmaduk erinç

\begin{tabular}{|c|c|c|c|}
\hline ini & \multirow{2}{*}{$+(s) I$} & $e c ̧ i+$ & \multirow{2}{*}{$+(s) I-n$ teg kulnnmaduk erinç } \\
\hline$o g(u) l$ & & $k a \eta+$ & \\
\hline
\end{tabular}

KD/23: yaraklıg kantan kelip yańa iltdi sünüglüg kantan kelipen süre iltdi; $\mathrm{BD} / 19$ : yarakhg kantan kelip yańa iltdi süyüglüg kantan süre i[ltdi]

\begin{tabular}{|c|c|c|c|}
\hline yarak & \multirow{2}{*}{ +lIg kantan kel- } & -ip yań- & \multirow{2}{*}{$-A$ iltdi } \\
\hline sünüg & & -ipen sür- & \\
\hline
\end{tabular}

\section{E2+K2}

KD/17: ilgerü yaşll ögüz şantuy yazıka tegi süledimiz kurıaru temir kapıgka tegi süledimiz kögmen aşa kı[rkız yirine tegi sü] (ledimiz); $\mathrm{BD} / 15$ : ilgerü yaşıl ögüz şantū yazıka tegi süledimiz kurıaru temir kapıgka tegi süledimiz kögmen aşa kırkız yirine tegi sü(ledimiz)

\begin{tabular}{|l|l|l|l|}
\hline il & + GArU & yaşıl ögüz şantuy yazı & + GA tegi süledimiz \\
\hline
\end{tabular}


104 / RumeliDE Journal of Language and Literature Studies 2018. Special Issue 4 (August)

Paralelism in Old Turkic Inscriptions / H. Ylldı (p. 93-122)

\begin{tabular}{|c|c|c|c|}
\hline kurı & & temir kapıg & \\
\hline- & - & kögmen aşa kırkız yir & $+I+\eta$ A tegi süledimiz \\
\hline
\end{tabular}

KD/21: inisi eçisin bilmez erti ogh kaym bilmez erti; $\mathrm{BD} / 18$ : inisi eçisin bilmez erti ogh kaym bilmez erti

\begin{tabular}{|c|c|c|c|}
\hline ini & \multirow{2}{*}{$+(s) I$} & $e c ̧ i$ & \multirow{2}{*}{$+(s) I-n$ bilmez erti } \\
\hline$o g(u) l$ & & kay & \\
\hline
\end{tabular}

KG/10-11: tirip il tutsıkının bunta urtum yayılıp ölsikinin yeme bunta urtum; BK/8: tirip [i]l tutsıkının bunta urtum yamllip ölsikipin [yeme] bunt[a urt]um

\begin{tabular}{|c|c|c|c|}
\hline tir- & \multirow{2}{*}{$-(I) p$} & il tut- & \multirow{2}{*}{$-s I k+I \eta+(I) n$ bunta urtum } \\
\hline yayıl- & & $\ddot{o l-}$ & \\
\hline
\end{tabular}

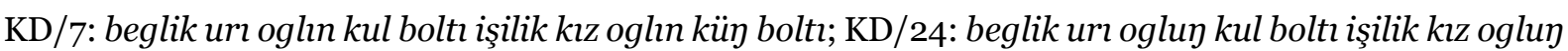
küy boltt; $\mathrm{BD} / 7$ : beglik urı oglın kul boltı işilik kız ogln küy boltı; $\mathrm{BD} / 20$ : beglik urı ogluyun kul kıltıg işilik [kız oglupun kü] kıltıg

\begin{tabular}{|c|c|c|c|c|c|c|c|c|}
\hline \multirow{2}{*}{$\mathrm{KD} / 7$} & beg & \multirow{8}{*}{$+l I k$} & urt & \multirow{2}{*}{ oglin } & kul & \multirow{4}{*}{ bol- } & \multirow{8}{*}{$+D I$} & \multirow{7}{*}{-} \\
\hline & işi & & $k u z$ & & $k \ddot{u} \eta$ & & & \\
\hline \multirow{2}{*}{$\mathrm{KD} / 24$} & beg & & urt & \multirow{2}{*}{ ogluy } & kul & & & \\
\hline & $i s ̧ i$ & & $k u z$ & & $k \ddot{u} \eta$ & & & \\
\hline \multirow{2}{*}{$\mathrm{BD} / 7$} & beg & & urt & \multirow{2}{*}{ oglin } & kul & \multirow{2}{*}{ kul- } & & \\
\hline & $i s ̧ i$ & & $k u z$ & & $k \ddot{u} \eta$ & & & \\
\hline \multirow{2}{*}{$\mathrm{BD} / 20$} & beg & & url & \multirow{2}{*}{ ogluyun } & kul & \multirow{2}{*}{ kll- } & & \\
\hline & $i s ̧ i$ & & $k \imath z$ & & $k \ddot{u} \eta$ & & & $-g$ \\
\hline
\end{tabular}

KG/10: çıgań bodunug kop kubratdım çıgań bodunug bay kıltım az bodunug üküş kıltım; KD/16: çıgańıg [bay kıltı azıg üküş kıltı]; KD/29: ölteçi bodunug tirgürü igit(t)im yalıy bodunug tonlug çıgań bodunug bay kıltım az bodunug üküş kıltım; BK/7: çıgań bodunug kop kubratdım çıań bodunug bay kıltım az bodunug üküş kıltım; BD/14: çıgańıg bay kıltı azıg üküş kıltı; BD/23-24: ölteçi bodunug t[irgü]rü igit(t)im yalıp bodunug tonlug kaltım çıań bodunug bay kıltım az bodunug üküş kaltım

\begin{tabular}{|c|c|c|c|c|c|c|}
\hline \multirow{3}{*}{$\mathrm{KG} / 10-\mathrm{BK} / 7$} & & \multirow{3}{*}{ bodun } & \multirow{3}{*}{$+(I) g$} & kop & kubrat- & \multirow{3}{*}{$-D I m$} \\
\hline & & & & bay & \multirow{2}{*}{ kal- } & \\
\hline & $a z$ & & & üküş & & \\
\hline
\end{tabular}




\begin{tabular}{|c|c|c|c|c|c|}
\hline \multirow{3}{*}{$\mathrm{KD} / 29$} & yalız & & tonlug & & \\
\hline & çıgań & & bay & \multirow{4}{*}{ kll- } & \multirow{2}{*}{$-D I m$} \\
\hline & $a z$ & & üküş & & \\
\hline \multirow{2}{*}{$\mathrm{KD} / 16-\mathrm{BD} / 14$} & çıgań & \multirow{2}{*}{-} & bay & & \multirow{2}{*}{$-D I$} \\
\hline & $a z$ & & üküş & & \\
\hline
\end{tabular}

\section{E2+K1}

$\mathrm{KD} / 13$ : ilsiremiş kagansıramış bodunug künedmiş kuladmış bodunug; $\mathrm{BD} / 11$ : ilsiremiş kagansıramış bodunug künedmiş kuladmış bodunug

\begin{tabular}{|c|c|c|c|c|c|}
\hline il & $+s I r A-$ & \multirow{2}{*}{$-m I s$} & kagan & $+s I r A-$ & \multirow{2}{*}{-mIş bodunug } \\
\hline$k \ddot{u \eta}$ & $+A d-$ & & $k u l$ & $+A d-$ & \\
\hline
\end{tabular}

KD/13-14: bodunug [anta itmiş] yabgug şadıg anta birmiş; BD/12: bodunug anta itmiş yabgug şadıg anta birmiş

\begin{tabular}{|c|c|c|c|}
\hline bodun & \multirow{2}{*}{$+(I)$ ganta } & it- & -mIş \\
\cline { 1 - 3 } & & bir- & \\
\hline
\end{tabular}

T-IIB/2: altun yışıg aşa keltimiz irtiş ögüzüg keçe keltimiz

\begin{tabular}{|c|c|c|c|}
\hline altun yış & \multirow{2}{*}{$+(I) g$} & aş- & \multirow{2}{*}{-A keltimiz } \\
\hline irtiş ögüz & & keç- & \\
\hline
\end{tabular}

T-IG/8: tabgaçgaru kunı seĐünüg ıdmış kıtańgaru toyra semig ıdmış

\begin{tabular}{|c|c|c|c|}
\hline tabgaç & \multirow{2}{*}{$+G A r U$} & kunı seĐün & \multirow{2}{*}{$+\operatorname{Ig} \imath d m \imath s$} \\
\hline kutań & & & \\
\hline
\end{tabular}

\section{$\mathbf{E 1}+\mathbf{K 8}$}

KD/32-33: ey ilki tadıkın çoruy boz (atıg binip tegdi ol at anta) ölti ikinti ışbara yamtar boz atıg binip tegdi ol at anta ölti üçünç yigen silig begin kedimlig torug atıg binip tegdi ol at anta ölti

\begin{tabular}{|c|c|c|c|c|}
\hline ej ilki & tadıkı çor & $+(I) \eta$ & boz & \\
\hline ikinti & ışbara yamtar & - & & atıg binip tegdi ol at anta ölti \\
\hline üçünç & yigen silig beg & $+(I) \eta$ & kedimlig torug & \\
\hline
\end{tabular}




\section{$\mathbf{E 1}+\mathrm{K} 5$}

KD/21: ilgerü kadırkan yışıg aşa bodunug ança konturtumuz ança itdimiz kurıaru keyü tarmanka tegi türk bodunug ança konturtumuz ança itdimiz; BD/17-18: ilgerü] kadırkan yış[ıg aşa] b[od]unug ança kontur[tumuz ança itdimiz] kurıgaru keyü tarbanka tegi türk bodunug ança kontur[tu]muz ança itdimiz

\begin{tabular}{|c|c|c|c|}
\hline \multirow{2}{*}{ il } & \multirow{3}{*}{+ GArU } & kadırkan yışıg aşa & \multirow{2}{*}{ bodunug ança konturtumuz ança itdimiz } \\
\cline { 1 - 1 } \cline { 1 - 1 } kurı & & keyü tarmanka tegi türk & \\
\hline
\end{tabular}

\section{$\mathbf{E 1}+\mathrm{K}_{3}$}

T-IG/13-14: yuyka kalın bolsar topulguluk alp ermiş yinçge yogun bolsar üzgülük alp ermiş

\begin{tabular}{|c|c|c|c|c|}
\hline yuyka & kalın & \multirow{2}{*}{ bolsar } & topul- & -gUlUk alp ermiş \\
\cline { 1 - 2 } yinçge & yogun & & üz- & \\
\hline
\end{tabular}

KD/20: kagan āt bunta biz birtimiz sinilim kunçuyug birtimiz; BD/17: kagan atıg bunta biz birtimiz similim ku[nçu]yug birtimiz

\begin{tabular}{|c|c|c|c|c|c|}
\hline \multirow{2}{*}{$\mathrm{KD} / 2 \mathrm{O}$} & kagan & $\bar{a} t$ & - & bunta biz & \multirow{4}{*}{ birtimiz } \\
\hline & sinilim & kunçuy & \multirow{3}{*}{$+(I) g$} & - & \\
\hline \multirow{2}{*}{$\mathrm{BD} / 17$} & kagan & at & & bunta biz & \\
\hline & sinilim & kunçuy & & - & \\
\hline
\end{tabular}

KD/4-5: inisi kagan bolmış erinç oghtı kagan bolmış erinç; BD/5: inisi kagan bolmış erin]ç ogltı kagan bolmış erinç

\begin{tabular}{|c|c|}
\hline ini & $+(s)$ I kagan bolmış erinç \\
\hline oglıt & \\
\hline
\end{tabular}

\section{$\mathbf{E 1}+\mathrm{K} 2$}

T-IG/13: yuyka erkli topulgah uçuz ermiş yinçge erkli üzgeli uçuz

\begin{tabular}{|c|c|c|c|c|}
\hline yuyka & \multirow{2}{*}{ erkli } & topul- & ermiş \\
\hline yinçge & & üz- & -GAlI uçuz & - \\
\hline
\end{tabular}

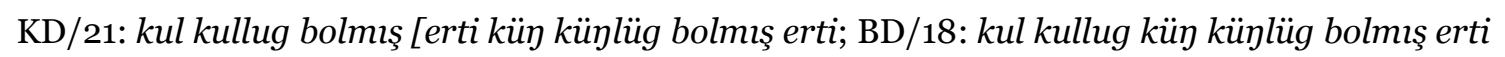




\begin{tabular}{|l|l|l|}
\hline$k u l$ & kul & + +lig bolmış erti \\
\hline$k \ddot{u} \eta$ & $k \ddot{\eta} \eta$ & \\
\hline
\end{tabular}

KD/12: süsi böri teg ermiş yagısı koń teg ermiş; $\mathrm{BD} / 11$ süsi böri teg ermiş yagısı koń teg ermiş

\begin{tabular}{|c|c|c|c|}
\hline sü & \multirow{2}{*}{$+(s) I$} & böri & teg ermiş \\
\hline yagı & koń & \\
\hline
\end{tabular}

KD/29: kutum bar üçün ülügüm bar üçün; BD/23: kutum ülügüm bar üçün

\begin{tabular}{|c|c|c|}
\hline \multirow{2}{*}{$\mathrm{KD} / 29$} & kut & \\
\cline { 2 - 3 } & ülüg & + \\
\hline $\mathrm{BD} / 23$ & kut... ülüg... & \\
\hline
\end{tabular}

KD/23-24: ilgerü] (barıma) bardıg kurıaru bargma bardıg; BD/19-20: ilgerü (bartgma) bardıg kurigaru (...) barrgma bardig

\begin{tabular}{|l|l|}
\hline il & \\
\hline kurl & +GArU barlgma bardig \\
\hline
\end{tabular}

$\mathrm{KD} / 14$ : biriye tabgaç bodun yagı ermiş yırıya baz kagan tokuz oguz yagı ermiş; $\mathrm{BD} / 12$ : biriye tabgaç bodun yagı ermiş yırıya baz kagan tokuz oguz yagı ermiş

\begin{tabular}{|c|c|c|c|}
\hline biri & \multirow{2}{*}{$+(y) A$} & tabgaç bodun & \multirow{2}{*}{ yagı ermis } \\
\hline yzr & & baz kagan tokuz oguz & \\
\hline
\end{tabular}

T-IG/11: tabgaç biridin yan teg kıtań öydin yan teg ben yırıdınta yan tegeyin

\begin{tabular}{|c|c|c|c|c|c|c|}
\hline tabgaç & biri & \multirow{3}{*}{$+D I n$} & & \multirow{3}{*}{ yan } & \multirow{3}{*}{ teg } & \multirow{2}{*}{ - } \\
\hline kutań & $\ddot{o} \eta$ & & & & & \\
\hline ben & yirl & & $+D A$ & & & -eyin \\
\hline
\end{tabular}

$\mathrm{KD} / 11$ : türk bodun yok bolmazun tiyin bodun bolçun tiyin; $\mathrm{BD} / 10$ : türk bodun yok bolmazun tiyin bodun bolçun tiyin

\begin{tabular}{|c|c|c|c|c|}
\hline \multirow{2}{*}{ türk } & bodun & yok & bolma- & -ÇUn tiyin \\
\hline \multirow{2}{*}{} & & - & bol- \\
\hline
\end{tabular}


108 / RumeliDE Journal of Language and Literature Studies 2018. Special Issue 4 (August)

Paralelism in Old Turkic Inscriptions / H. Ylldız (p. 93-122)

\section{$\mathbf{E} 1+\mathrm{K} 1$}

$\mathrm{KG} / 1$ : biriye şad apıt begler yırıya tarkat buyruk begler; BK/1: biriye şad apıt begler yırıya tarkat buyruk begler

\begin{tabular}{|c|c|c|c|}
\hline \multirow{2}{*}{ biri } & \multirow{3}{*}{$+(y) A$} & şad & apıt \\
\cline { 1 - 3 } yırı & & tarkat & begler \\
\cline { 3 - 4 } & & & buyruk \\
\hline
\end{tabular}

$\mathrm{KD}$ /2: ilgerü kadırkan yışka tegi kirü temir kapıgka tegi; $\mathrm{BD} / 3-4$ : ilgerü kadırkan yışka tegi kirü] temir kapıgka tegi

\begin{tabular}{|c|c|c|}
\hline ilgerü & kadırkan yış & + +GA tegi \\
\hline kirü & temir kapıg & \\
\hline
\end{tabular}

KD/18-19: [bilmedükin] üçün bizine yamll[t]ukın üçün; BD/16: bilmedükin üçün bizine yałıltukın yazıntukın üçün

\begin{tabular}{|c|c|c|}
\hline & bilme- & \multirow{2}{*}{-DUk+I+n üçün } \\
\hline bizige & yayl-yazın- & \\
\hline
\end{tabular}

KD/19: kaganı ölti buyrukı begleri yeme ölti; BD/16: kaganı ölti buyrukı begleri yeme ölti

\begin{tabular}{|c|c|c|c|}
\hline kagan & \multirow{2}{*}{$+I$} & - & \multirow{2}{*}{ ölti } \\
\hline buyruk... begler... & & yeme & \\
\hline
\end{tabular}

KD/20: özi yamıltı kaganı ölti bodunı küy kul boltı; BD/17: özi yazıntı kaganı ölti bodunı küy kul boltı

\begin{tabular}{|c|c|c|c|}
\hline$\ddot{o} z$ & \multirow{3}{*}{$+I$} & yayzl- & \multirow{3}{*}{$-D I$} \\
\hline kagan & & $\ddot{o l}-$ & \\
\hline bodun & & kǖ kul bol- & \\
\hline
\end{tabular}

BK/12: kazganu birtim iti birtim

\begin{tabular}{|l|l|}
\hline kazgan- & -I birtim \\
\hline it- & \\
\hline
\end{tabular}

KD/36: bir erig okun urtı iki erig udu aşuru sançdı

\begin{tabular}{|l|l|l|l|}
\hline bir & erig & okun ur- & $-D I$ \\
\hline
\end{tabular}


$\mathrm{KD} / 3$ : begleri yeme bodun yeme; $\mathrm{BD} / 4$ : begleri yeme bodun [yeme

\begin{tabular}{|l|l|}
\hline begler & +Iyeme \\
\hline bodun & \\
\hline
\end{tabular}

T-IIG/5: tabgaçka yiti yigirmi süyüşdi kıtańka yiti süyüşdi oguzka bişs süyüşdi

\begin{tabular}{|c|c|c|c|}
\hline tabgaç & \multirow{3}{*}{$+G A$} & yiti yigirmi & \multirow{3}{*}{ süyüşdi } \\
\hline kutań & & yiti & \\
\hline oguz & & biş & \\
\hline
\end{tabular}

T-ID/1: türk bodun kl(linga)lı türk kagan olurgah

\begin{tabular}{|l|l|l|}
\hline \multirow{2}{*}{ türk } & bodun kalin- & -GAlI \\
\hline
\end{tabular}

KK/11: közde yaş kelser tıda köyülte sıgıt kelser yanturu

\begin{tabular}{|c|c|c|c|c|}
\hline köz & \multirow{3}{*}{$+D A$} & yaş & kelser & tıd-a \\
\hline köyül & slgıt & & yantur-u \\
\hline
\end{tabular}

\subsection{Kavram Alanı Bakımından Paralelizmler}

Köl Tigin, Bilge Kağan ve Tonyukuk I-II bengü taşlarındaki 68 paralelizm örneği arasında bazı kelimelerin aynı kavram alanında olduğu görülmektedir. Aynı kavram alanında olan ve birden fazla örneği bulunan 85 paralelizm verisine rastlanmaktadır. 43 veri ise tek örnekli paralelizmlerdir.

\subsubsection{Aynı Kavram Alanında Olup Birden Fazla Örneği Bulunan Paralelizmler}

Bengü taşlarda aynı kavram alanında birden fazla örneği bulunan 89 paralelizm verisi 21 başlıkta gruplandırılabilir. İkinci grup hariç, diğer grupların alt başlıkları yoktur.

\subsubsection{1. il / biri / kurı / yırı/ kirü}

KG/1: biriye şad apıt begler yırıya tarkat buyruk begler; BK/1: biriye şad apıt begler yırıya tarkat buyruk begler

KG/2: ilgerü kün togsık(k)a birigerü kün ortusınaru kurıgaru kün batsıkıрa yırıgaru tün ortusınaru; BK/1-2: ilgerü kün] togsıkına birigerü kün ortusınaru kurıgaru kün batsıkına yırıgaru tün ortusıjaru 
KG/3-4: ilgerü şantuy yazıka tegi süledim taluyka kiçig tegmedim birigerü tokuz ersinke tegi süledim töpütke kiçig tegmedim kurıgaru yinçü ögüz keçe temir kapıgka tegi süledim yırıaru yir bayırku yirine tegi süledim; BK/2-3: ilge[rü ş]antuy [yazlka tegi süledim taluyka kiçig tegmedim b]irigerü t[okuz] ersinke tegi süledim töpütke kiçig tegmedim kurıgaru yinçü ögüz keçe temir kapıgka tegi süledim yırıgaru yir bayırku yirine tegi süle[dim]

$\mathrm{KD}$ /2: ilgerü kadırkan yışka tegi kirü temir kapıgka tegi; $\mathrm{BD} / 3-4$ : ilgerü kadırkan yışka tegi kirü] temir kapıgka tegi

KD/8: ilgerü kün togsıkda bük ili kaganka tegi süleyü birmiş kurıaru temir kapıgka tegi süleyü birmiş; $\mathrm{BD} / 8$ : ilgerü kün togsık(k)a bük ili kaganka tegi süleyü birmiş kurıgaru temir kapıgka tegi süleyü birmiş

KD/17: ilgerü yaşll ögüz şantuฤ yazıka tegi süledimiz kurıaru temir kapıgka tegi süledimiz kögmen aşa kı[rkız yirine tegi sü] (ledimiz); $\mathrm{BD} / 15$ : ilgerü yaşıl ögüz şantū yazıka tegi süledimiz kurıaru temir kapıgka tegi süledimiz kögmen aşa kırkız yirine tegi sü(ledimiz)

KD/21: ilgerü kadırkan yışıg aşa bodunug ança konturtumuz ança itdimiz kurıgaru kemü tarmanka tegi türk bodunug ança konturtumuz ança itdimiz; BD/17-18: ilgerü] kadirkan yış[ıg aşa] b[od]unug ança kontur[tumuz ança itdimiz] kurıgaru keĐü tarbanka tegi türk bodunug ança kontur[tu]muz ança itdimiz

KD/23-24: ilgerü] (barıma) bardıg kurıaru barıma bardıg; BD/19-20: ilgerü (barıma) bardıg kurgaru (...) bartgma bardıg

KD/14: biriye tabgaç bodun yagı ermiş yırıya baz kagan tokuz oguz yagı ermiş; $\mathrm{BD} / 12$ : biriye tabgaç bodun yagı ermiş yırıya baz kagan tokuz oguz yagı ermiş

T-IG/11: tabgaç biridin yan teg kıtań öydin yan teg ben yırıdınta yan tegeyin

T-IG/14: öyre kutanda biriye tabgaçda kurıya kordanta yırıya oguzda

\subsubsection{2. il / kagan / bodun / öz}

\section{il / kagan}

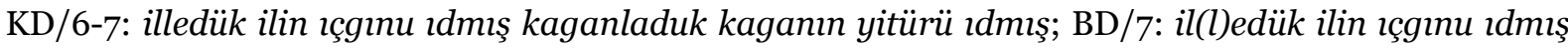
kaganladuk kaganın yitürü ıdmış

KD/9: illig bodun ertim ilim amtı kanı kimke ilig kazganur men tir ermiş kaganlıg bodun ertim kaganım kanı ne kaganka işig küçüg birür men tir ermiş; BD/8-9: illig bodun [ertim ilim amtı kanı kimke ilig kazganur men tir ermiş] kaganlgg bodun ertim kaganım kanı ne kaganka işig küçüg birür men tir ermiş

KD/13: ilsiremiş kagansıramış bodunug küyedmiş kuladmış bodunug; $\mathrm{BD} / 11$ : ilsiremiş kagansıramış bodunug kǖedmiş kuladmış bodunug 
$\mathrm{KD} / 15$ : illigig ilsiretmiş kaganlıgıg kagansıratmış yagıg baz kılmış; $\mathrm{KD} / 18$ : illigig ilsiretdimiz kaganlıgıg kagansıratdımız; $\mathrm{BD} / 13$ : illigig ilsiretmiş kaganlıgıg kagansıratmış yagıg baz kılmış; $\mathrm{BD} / 15$ : [illigig ilsiretdimiz kaganlıgıg kagansuratdımız]

\section{öz / kagan}

T-IID/4: ilteriş kagan kazganmasar udu ben özüm kazganmasar; T-IIK/1: ilteriş kagan kazganmasar yok erti erser ben özüm bilge tunukuk kazganmasar ben yok ertim erser

KD/20: özi yayıltı kaganı ölti bodunı küy kul boltı; BD/17: özi yazıntı kaganı ölti bodunı küy kul boltı

\section{bodun / kagan}

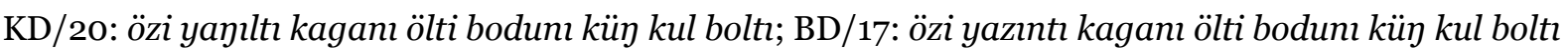
T-ID/1: türk bodun kı(linga)lı türk kagan olurgah

\section{il / bodun}

T-IID/6: il yeme il boltı bodun yeme bodun boltı

ini / eçi

KD/4-5: inisi kagan bolmış erinç oglıtı kagan bolmış erinç; BD/5: inisi kagan bolmış erin]ç oghtı kagan bolmış erinç

KD/5: inisi eçisin teg kulnmaduk erinç oglı kayın teg kulınmaduk erinç; $\mathrm{BD} / 5^{-6}$ : inisi eçisin teg kulınmaduk erinç oglı kayın teg kulınmaduk erinç

KD/21: inisi eçisin bilmez erti oglı kayın bilmez erti; $\mathrm{BD} / 18$ : inisi eçisin bilmez erti ogh kayın bilmez erti

\section{kay / og(u)l / oglit}

KD/4-5: inisi kagan bolmış erinç oghtı kagan bolmış erinç; BD/5: inisi kagan bolmış erin]ç oghtı kagan bolmış erinç

$\mathrm{KD} / 5$ : inisi eçisin teg kulınmaduk erinç oglı kayın teg kulınmaduk erinç; $\mathrm{BD} / 5-6$ : inisi eçisin teg kılınmaduk erinç oglı kayın teg kulınmaduk erinç

KD/21: inisi eçisin bilmez erti ogh kayın bilmez erti; $\mathrm{BD} / 18$ : inisi eçisin bilmez erti ogh kayın bilmez erti

\section{begler / bodun}

$\mathrm{KD} / 3$ : begleri yeme bodun yeme; $\mathrm{BD} / 4$ : begleri yeme bodun [yeme

KD/6: begleri bodun tüzsüz üçün tabgaç bodun tebligin kürlüg üçün armakçısın üçün inili eçili kikşürtükin üçün begli bodunlıg yoyaşurtukın üçün; BD/6-7: begleri bodun tüzsüz üçün tabgaç bodun 
tebli[gin] kürlügin [üçün armakçı]sın üçün inili [eçili kikşürtükin üçün begli bodunhg] yogaşurtukkn üçün

\section{bin- / oplayu teg-}

KD/35: köl tigin bayırkun(uy ak adgrrı) binip oplayu tegdi; KD/37: köl tigin başgu boz at binip tegdi; KK/2: alp şalçı akın binip oplayu tegdi; KK/3-4: köl tigin alp şalçı akın binip (oplayu tegd)i; KK/5: köl tigin azman akıg binip oplayu tegdi; KK/5: köl tigin az yagızı binip oplayu tegip; KK/6: köl tigin azman akm binip tegdi; KK/7-8: köl tigin az yagızın binip tegdi; KK/8-9: köl tigin ögsüz akın binip

sab / agi

KG/5: sabı süçig agısı yımşak; BK/4: sabı süçig agısı yımşak; KG/5: süçig sabın yımşak agın; BK/4: süçig sabın yımşak agın; KG/6: süçig sabına yımşak agısına; BK/5: süçig sabına yımşak agısına

\section{süçig / yımşak}

KG/5: sabı süçig agısı yımşak; BK/4: sabı süçig agısı yımşak; KG/5: süçig sabın yımşak agın; BK/4: süçig sabın yımşak agın; KG/6: süçig sabına yımşak agısına; BK/5: süçig sabına yımşak agısııa

\section{bilge / alp}

KG/6: edgü bilge kişig edgü alp kişig; BK/4: edgü [bil]ge kişig edgü alp kişig; KD/3: bilge kagan ermiş alp kagan ermiş; $\mathrm{BD} / 4$ : bilge kagan ermiş alp kagan ermiş; $\mathrm{KD} / 3$ : bilge ermiş erinç alp ermiş erinç; $\mathrm{BD} / 4$ : bilge ermiş erinç alp ermiş erinç; $\mathrm{T}-\mathrm{ID} / 4$ : kaganı alp ermiş ayguçısı bilge ermiş; T-IK/5: kagamı alp ermiş ayguçısı bilge ermiş; T-IIG/4-5: bilgesin üçün alpın üçün

\section{çıań / bay}

KG/10: çıgań bodunug kop kubratdım çıgań bodunug bay kaltım az bodunug üküş kıltım; KD/16: çıgańıg [bay kıltı azıg üküş kıltı]; KD/29: ölteçi bodunug tirgürü igit(t)im yalıy bodunug tonlug çıgań bodunug bay klltım az bodunug üküş kılttm; BK/7: çıgań bodunug kop kubratdım çıgań bodunug bay kıltım az bodunug üküş kıltım; BD/14: çıgańng bay kultı azıg üküş kıltt; BD/23-24: ölteçi bodunug t[irgü]rü igit(t)im yalıp bodunug tonlug kaltım çıań bodunug bay kılttm az bodunug üküşs klttım

\section{az / üküş}

KG/10: çıgań bodunug kop kubratdım çıgań bodunug bay kıltım az bodunug üküş kılttrm; KD/16: çıgańıg [bay kıltı azıg üküş kaltı]; KD/29: ölteçi bodunug tirgürü igit(t)im yalıy bodunug tonlug çıgań bodunug bay kıltım az bodunug üküş kıltım; BK/7: çıgań bodunug kop kubratdım çıań bodunug bay kıltım az bodunug üküş kıltım; BD/14: çıgańıg bay kıltı azıg üküş kıltı; BD/23-24: ölteçi bodunug t[irgü]rü igit(t)im yahy bodunug tonlug kıltım çıań bodunug bay kıltım az bodunug üküşs kıltım

\section{üze / asra}

KD/1: üze kök teyri asra yagız yir; $\mathrm{KD} / 22$ : üze teyri basmasar asra yir telinmeser; $\mathrm{BK} / 10$ : üze teyri asra yir; $\mathrm{BD} / 2$ : üze kök teyri asra yagız yir; $\mathrm{BD} / 18$ : üze tẹri basma[sar asra] yir telinmeser 


\section{teyri / yir}

$\mathrm{KD} / 1$ : üze kök teyri asra yagız yir; $\mathrm{KD} / 22$ : üze teyri basmasar asra yir telinmeser; $\mathrm{BK} / 10$ : üze teyri asra yir; $\mathrm{BD} / 2$ : üze kök teyri asra yagız yir; $\mathrm{BD} / 18$ : üze teyri basma[sar asra] yir telinmeser

\section{başlıg / tizlig}

KD/2: başlıgıg yüküntürmiş tizligig sökürmiş; $\mathrm{KD} / 15$ : tizligig sökürmiş başlıgıg yüküntürmiş; $\mathrm{KD} / 18$ : tizligig sökürtümüz başhlgrg yüküntürtümüz; BK/10: b)aş(l)ıgıg yüküntürtüm tizligig sökürtüm; BD/3: başlıgıg yüküntürmiş tizlig[ig sökürmiş; $\mathrm{BD} / 13$ : tizligig sökürmiş başlıgıg yüküntürmiş; $\mathrm{BD} / 15$ 16: tizligig] sökürtümüz başhgıg yüküntürtümüz

\section{yüküntür- / sökür-}

$\mathrm{KD} / 2$ : başlıgıg yüküntürmiş tizligig sökürmiş; $\mathrm{KD} / 15$ : tizligig sökürmiş başlıgıg yüküntürmiş; $\mathrm{KD} / 18$ : tizligig sökürtümüz başlıgg yüküntürtümüz; BK/10: b)aş(l)ıgıg yüküntürtüm tizligig sökürtüm; $\mathrm{BD} / 3$ : başlıgıg yüküntürmiş tizlig[ig sökürmiş; $\mathrm{BD} / 13$ : tizligig sökürmiş başhgıg yüküntürmiş; $\mathrm{BD} / 15$ 16: tizligig] sökürtümüz başhgıg yüküntürtümüz

\section{topul- / ̈̈z-}

T-IG/13: yuyka erkli topulgah uçuz ermiş yinçge erkli üzgeli uçuz

T-IG/13-14: yuyka kalın bolsar topulguluk alp ermiş yinçge yogun bolsar üzgülük alp ermiş

\section{beglik / işilik}

$\mathrm{KD}$ /7: beglik urı oglın kul boltı işilik kız oglın kü円 boltı; KD/24: beglik urı oglū kul boltı işilik kız ogluy küy boltt; BD/7: beglik urı ogln kul boltı işilik kız ogln küy boltı; BD/20: beglik urı ogluyun kul kıltıg işilik [kız ogluyun kü]p kıltıg

\section{tün / küntüz}

KD/27: tün udımadım küntüz olurmadı[m]; BD/22: tün udımadım küntüz olurmadım; T-ID/5: tün yeme udısıkım kelmez erti (kün yeme) olursıkım kelmez erti; T-IID/2: tün udımatı küntüz olurmatı

KG/2: ilgerü kün togsık(k)a birigerü kün ortusınaru kurıgaru kün batsıkıga yırıgaru tün ortusıgaru;

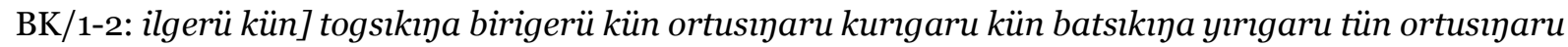

\section{kul / küy kulad- küyed-}

KD/21: kul kullug bolmış [erti küy küylüg bolmış erti; BD/18: kul kullug küy küylüg bolmış erti

KD/20: özi yayıltı kaganı ölti bodunı küy kul boltı; BD/17: özi yazıntı kaganı ölti bodunı küy kul boltı

KD/13: ilsiremiş kagansıramış bodunug künedmiş kuladmış bodunug; $\mathrm{BD} / 11$ : ilsiremiş kagansıramış bodunug küyedmiş kuladmış bodunug 


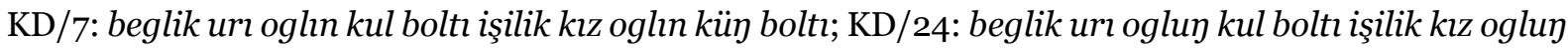
küy boltı; $\mathrm{BD} / 7$ : beglik urı oglın kul boltn işilik kız ogln küy boltı; $\mathrm{BD} / 20$ : beglik urı ogluyun kul kaltıg işilik [kız oglupun kü] k kıltıg

\section{tabgaç / kitań / oguz}

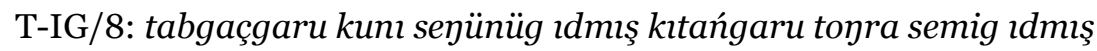

T-IIG/5: tabgaçka yiti yigirmi süyüşdi kıtańka yiti süyüşdi oguzka bişs süĐüşdi

T-IG/11: tabgaç biridin yan teg kutań öydin yan teg ben yırıdınta yan tegeyin

T-IG/14: öyre kıtańda biriye tabgaçda kurıya kordanta yırıya oguzda

\section{yuyka / yinçge}

T-IG/13: yuyka erkli topulgah uçuz ermiş yinçge erkli üzgeli uçuz

T-IG/13-14: yuyka kalın bolsar topulguluk alp ermiş yinçge yogun bolsar üzgülük alp ermiş

\subsubsection{Aynı Kavram Alanında Olup Tek Örneği Bulunan Paralelizmler}

Bengü taşlarda aynı kavram alanında tek örneği bulunan 43 paralelizm verisi bulunmaktadır.

udi- / olur-

KD/27: tün udımadım küntüz olurmadı[m]; BD/22: tün udımadım küntüz olurmadım; T-ID/5: tün yeme udısıkım kelmez erti (kün yeme) olursıkım kelmez erti; T-IID/2: tün udımatı küntüz olurmatı

\section{biligsiz / yablak}

$\mathrm{KD} / 5$ : biligsiz kagan olurmış erinç yablak kagan olurmış erinç; $\mathrm{BD} / 6$ : biligsiz kagan olurmış erinç yablak kagan olurmış erinç

\section{türk / tabgaç}

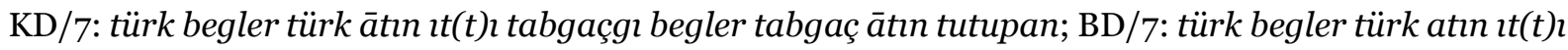
tabga[çgı] begler tabga[ç àtın tutupan

\section{yaraklıg / süyüglüg}

KD/23: yaraklıg kantan kelip yańa iltdi sünüglüg kantan kelipen süre iltdi; $\mathrm{BD} / 19$ : yaraklıg kantan kelip yańa iltdi süyüglüg kantan süre i[ltdi]

yan- / sür-

KD/23: yaraklig kantan kelip yańa iltdi süyüglüg kantan kelipen süre iltdi; $\mathrm{BD} / 19$ : yaraklg kantan kelip yańa iltdi sünüglüg kantan süre i[ltdi] 


\section{bolmazun / bolçun}

KD/11: türk bodun yok bolmazun tiyin bodun bolçun tiyin; $\mathrm{BD} / 10$ : türk bodun yok bolmazun tiyin bodun bolçun tiyin

\section{kay / ög}

KD/11: kayım iltiriş kaganı ögüm ilbilge katunug; KD/25: kayım kaganı ögüm katunug; $\mathrm{BD} / 10$ : kayım iltiriş kaganı ögüm ilbilge katunug; BD/20-21: kayım kaganıg ögüm katunug

\section{kagan / katun}

$\mathrm{KD} / 11$ : kayım iltiriş kaganıg ögüm ilbilge katunug; KD/25: kayım kaganı ögüm katunug; BD/10: kayım iltiriş kaganı ögüm ilbilge katunug; BD/20-21: kayım kaganıg ögüm katunug

\section{balık / tag}

KD/12: balıkdakı tagıkmış tagdakı inmiş; BD/10-11: ba]l[ık]da[kı taşıkmış tagdakı] inmiş

sü / yagı

KD/12: süsi böri teg ermiş yagısı koń teg ermiş; $\mathrm{BD} / 11$ süsi böri teg ermiş yagısı koń teg ermiş

\section{böri / koń}

$\mathrm{KD} / 12$ : süsi böri teg ermiş yagısı koń teg ermiş; $\mathrm{BD} / 11$ süsi böri teg ermiş yagısı koń teg ermiş

\section{bodun / yabgu / şad}

KD/13-14: bodunug [anta itmiş] yabgug şadıg anta birmiş; BD/12: bodunug anta itmiş yabgug şadıg anta birmiş

\section{bilme- / yayıl-}

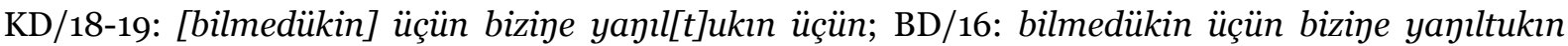
yazıntukın üçün

\section{kagan / buyruk / begler}

KD/19: kaganı ölti buyrukı begleri yeme ölti; BD/16: kaganı ölti buyrukı begleri yeme ölti

\section{kan / sünük}

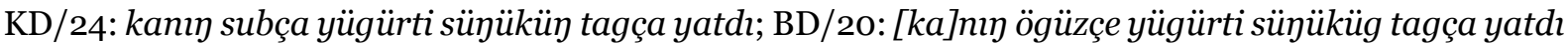

\section{iç / taş}

$\mathrm{KD}$ /26: içre aşsız taşra tonsuz; $\mathrm{BD} / 21$ : içre aşsız taşra tonsuz 
116 / RumeliDE Journal of Language and Literature Studies 2018. Special Issue 4 (August)

Paralelism in Old Turkic Inscriptions / H. Ylldız (p. 93-122)

sub / tag

KD/24: kanı subça yügürti süyüküy tagça yatdr; BD/20: [ka]nı ögüzçe yügürti süyüküg tagça yatdı

aș / ton

$\mathrm{KD}$ /26: içre aşsız taşra tonsuz; $\mathrm{BD} / 21$ : içre aşsız taşra tonsuz

kut / ülüg

KD/29: kutum bar üçün ülügüm bar üçün; BD/23: kutum ülügüm bar üçün

kör- / bil-

KK/10: körür közüm körmez teg bilir biligim bilmez teg

köz / köyül

KK/11: közde yaş kelser tıda köyülte sıgıt kelser yanturu

köz / bilig

KK/10: körür közüm körmez teg bilir biligim bilmez teg

yaş / sıgıt

KK/11: közde yaş kelser tıda köyülte sıgıt kelser yanturu

\section{köz / kulkak}

BK/11: közün körmedük kulkakın eşidmedük

kazgan- / it-

BK/12: kazganu birtim iti birtim

içik- / öl-

BD/37: içikigme içikdi bodun boltı ölügme ölti

kış / yaz

BG/2: otuz artukı sekiz yaşıma kışın kıtań tapa süledim (otuz artukı tokuz ya)şıma yazın tatabı tapa sü(ledim...)

\section{kitań / tatabı}

BG/2: otuz artukı sekiz yaşıma kışın kıtań tapa süledim (otuz artukı tokuz ya)şıma yazın tatabı tapa sü(ledim...) 


\section{şad / kagan}

BG/9: tokuz yigirmi yıl şad olurtum toku(z yigir)mi yıl kagan olurtum

atlig / yadag

T-IB/4: iki ülügi atllg erti bir ülügi yadag erti

aş- / keç-

T-IIB/2: altun yışıg aşa keltimiz irtiş ögüzüg keçe keltimiz

ayguçı / yaguçı

T-IIG/5-6: ayguçı(sı) yeme ben ök ertim yagıçısı yeme ben ök ertim

\section{kızl / kara}

T-IID/2: kzzıl kanım töküti kara terim yügürti

kan / ter

T-IID/2: kızll kanım töküti kara terim yügürti

\section{yaraklıg / tügünlüg}

T-IID/4: yaraklıg yagıg yeltürmedim tügünlüg atıg yügürtmedim

yagi / at

T-IID/4: yaraklıg yagıg yeltürmedim tügünlüg atıg yügürtmedim

yeltür- / yügürt-

T-IID/4: yarakhg yagrg yeltürmedim tügünlüg atıg yügürtmedim

rrak / yaguk

KG/7: rrak erser yablak agı birür yaguk erser edgü agı birür; BK/5: ırak erser yablak agı birür yaguk erser edgü agı birür

\section{yablak / edgü}

KG/7: ırak erser yablak agı birür yaguk erser edgü agı birür; BK/5: ırak erser yablak agı birür yaguk erser edgü agı birür

\section{tir- / yayıl-}

KG/10-11: tirip il tutsıkının bunta urtum yamılı ölsikinin yeme bunta urtum; BK/8: tirip [i]l tutsıkımın bunta urtum yayllp ölsikinin [yeme] bunt[a urt]um 
il tut- / öl-

KG/10-11: tirip il tutsıkının bunta urtum yamılı ölsikimin yeme bunta urtum; BK/8: tirip [i]l tutsıkının bunta urtum yamllp ölsikinin [yeme] bunt[a urt]um

tut- / it-

KD/1: tuta birmiş iti birmiş; $\mathrm{BD} / 3$ : tuta birmiş iti birmiş

Içgın- / yitür-

KD/6-7: illedük ilin ıçgınu ıdmış kaganladuk kaganın yitürü ıdmış; BD/7: il(l)edük ilin ıçgınu ıdmış kaganladuk kaganın yitürü ıdmış

\section{Sonuç}

Eski Türk bengü taşlarındaki paralelizm örnekleri ekler bakımından analiz edildiğinde şu tabloya ulaşılmaktadır.

Tablo 1. Eski Türk Bengü Taşlarındaki Paralelizm Örneklerinde Eklerin Analizi

\begin{tabular}{|c|c|c|c|}
\hline Ek & İşlev & Kullanıldığı Örnek Numaraları & Siklık \\
\hline$+(\mathbf{s}) \mathbf{I}$ & İYE/3TK & $\begin{array}{l}12,23,23,23,25,26,27,28,30,30,32,33,33,34,34,36 \\
37,37,49,52,60,61,62,65\end{array}$ & 24 \\
\hline$+(I) g$ & YÜK & $10,11,14,16,23,24,27,40,42,43,44,48$ & 12 \\
\hline$+\mathbf{n}$ & YÜK & $12,23,23,26,27,30,33,33,34,37,38,6$ o & 12 \\
\hline$-\mathbf{D I}$ & GGZ & $10,13,14,19,20,22,27,39,40,62,64$ & 11 \\
\hline$+\mathbf{G A r} \mathbf{U}$ & YG & $25,25,28,31,36,44,46,54$ & 8 \\
\hline$+(I) \mathrm{m}$ & İYE/1TK & $16,20,22,24,29,53$ & 6 \\
\hline$+(\mathbf{y}) \mathbf{A}$ & YÖN & $15,25,31,31,55,58$ & 6 \\
\hline$+\mathbf{G A}$ & YÖN & $24,28,28,36,59,66$ & 6 \\
\hline+119 & İIYE & $10,11,14,24,35,51$ & 6 \\
\hline$+\mathbf{y A}$ & YÖN & $25,28,33,33,36$ & 5 \\
\hline$+\mathbf{D A}$ & BUL & $15,17,31,68$ & 4 \\
\hline -dUk & $\mathrm{SF}$ & $12,23,26,60$ & 4 \\
\hline$-\mathbf{m}$ & $1 \mathrm{TK}$ & $10,14,22,40$ & 4 \\
\hline$-\mathbf{m A} \mathbf{A}$ & FFYE & $10,12,21,22$ & 4 \\
\hline -mIş & ÖGZ & $11,14,17,42$ & 4 \\
\hline
\end{tabular}




\begin{tabular}{|c|c|c|c|}
\hline -sIk & $\mathrm{SF}$ & $22,25,31,38$ & 4 \\
\hline$+(I) y$ & İYE/2TK & $13,38,45$ & $\mathbf{3}$ \\
\hline$+\mathbf{r A}$ & YG & 15,18 & 2 \\
\hline +sIrA- & İFYE & 11,41 & 2 \\
\hline$-\mathbf{A}$ & $\mathrm{ZF}$ & 35,43 & 2 \\
\hline -gAlI & $\mathrm{ZF}$ & 50,67 & 2 \\
\hline -Ip(An) & $\mathrm{ZF}$ & 35,38 & 2 \\
\hline$-\mathbf{X r}$ & GEN & 23,24 & 2 \\
\hline$-(I) g$ & $2 \mathrm{TK}$ & 39 & $\mathbf{1}$ \\
\hline -(I)gmA & SF & 19 & $\mathbf{1}$ \\
\hline+ Ad- & İFYE & 41 & $\mathbf{1}$ \\
\hline$+\mathbf{c} \mathrm{A}$ & EŞT & 13 & $\mathbf{1}$ \\
\hline$+\mathbf{c ̧ I}$ & İ̈YE & 32 & $\mathbf{1}$ \\
\hline +DIn & ÇIK & 56 & $\mathbf{1}$ \\
\hline$+\mathbf{k I}$ & AİT & 17 & $\mathbf{1}$ \\
\hline$+\mathbf{l A}-$ & İFYE & 26 & $\mathbf{1}$ \\
\hline$+\mathbf{l I}+\mathbf{l I}$ & $\mathrm{BAĞ}$ & 23 & $\mathbf{1}$ \\
\hline +lIk & İ̈YE & 39 & $\mathbf{1}$ \\
\hline$+\mathbf{S I z}$ & İ̈YE & 18 & $\mathbf{1}$ \\
\hline -ÇUn & EMR/3TK & 57 & $\mathbf{1}$ \\
\hline -gUlUk & SF & 47 & $\mathbf{1}$ \\
\hline$-\mathbf{I}$ & $\mathrm{ZF}$ & 63 & $\mathbf{1}$ \\
\hline -mAtI & $\mathrm{ZF}$ & 22 & $\mathbf{1}$ \\
\hline$-\mathbf{m A z}$ & SF & 29 & $\mathbf{1}$ \\
\hline -mIş & SF & 41 & $\mathbf{1}$ \\
\hline$-\mathbf{m I z}$ & 1 ÇK & 14 & $\mathbf{1}$ \\
\hline$-\mathbf{s A r}$ & ŞRT & 21 & $\mathbf{1}$ \\
\hline$-t-$ & FFYE & 11 & $\mathbf{1}$ \\
\hline
\end{tabular}

\footnotetext{
Adres $\mid$ Adress1 


\begin{tabular}{|l|l|l|r|}
\hline$-\mathbf{U}$ & ZF & 26 & $\mathbf{1}$ \\
\hline $\mathbf{- X r}$ & SF & 29 & $\mathbf{1}$ \\
\hline
\end{tabular}

Bu tabloya göre paralelizm örneklerinde en sık kullanılan ekler isim çekim ekleridir. Sıktan aza doğru yapılan sıralamada, en sık kullanılan 10 ek arasında fiil çekim eki olarak yalnızca, beşinci sıradaki görülen geçmiş zaman kipi yer almaktadır.

Bengü taşlardaki paralelizm örneklerinin kavram alanları bakımından yapılan analizlerinde ise birden fazla paralelizm örneği bulunan kelimelerle ilgili olarak şu tabloyla karşılaşılmaktadır:

Tablo 2. Bengü Taşlardaki Kavram Alamı Ortak Kelimelerin Analizi

\begin{tabular}{|c|c|}
\hline Kavram Alanı Ortak Kelimeler & Örnek Sayısı \\
\hline il / biri / kurı / yırı/ kirü & 11 \\
\hline il / kagan / bodun / öz & 9 \\
\hline bin- / oplayu teg- & 6 \\
\hline bilge / alp & 5 \\
\hline kul / küy & 4 \\
\hline tün / küntüz & 4 \\
\hline tabgaç / kıtań / oguz & 4 \\
\hline ini / eçi & 3 \\
\hline kay / og(u)l / oglıt & 3 \\
\hline sab / agi & 3 \\
\hline süçig / yımşak & 3 \\
\hline çıań / bay & 3 \\
\hline az / üküuş & 3 \\
\hline üze / asra & 3 \\
\hline tepri / yir & 3 \\
\hline başlıg / tizlig & 3 \\
\hline yüküntür- / sökür- & 3 \\
\hline beglik / işilik & 3 \\
\hline $\operatorname{og}(\mathbf{u}) \mathbf{l} / \mathbf{k a z}$ & 3 \\
\hline begler / bodun & 2 \\
\hline
\end{tabular}




\begin{tabular}{|l|l|}
\hline topul- / üz- & 2 \\
\hline yuyka / yinçge & 2 \\
\hline
\end{tabular}

Bunlar dışında tek örnekli ancak aynı kavram alanına sahip 43 veri daha bulunmaktadır:

aş- / keç-; aş / ton; athg / yadag; ayguçı / yaguçı; balk / tag; biligsiz / yablak; bilme- / yamıl-; bodun / yabgu / şad; bolmazun / bolçun; böri / koń; ıçgın- / yitür-; rrak / yaguk; iç / taş; içik- / öl-; il tut- / öl-;

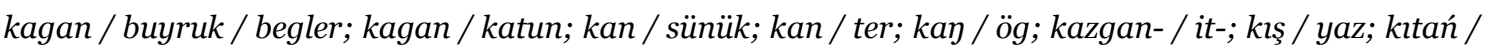
tatabı; kızll / kara; kör- / bil-; köz / bilig; köz / köyül; köz / kulkak; kut / ülüg; sub / tag; sü / yagı; şad / kagan; tir- / yazıl-; tut- / it-; türk / tabgaç; udl- / olur-; yablak / edgü; yagı / at; yan- / sür-; yaraklg / süyüglüg; yaraklg / tügünlüg; yaş / slgtt; yeltür- / yügürt-

Yukarıda tablodan ve diğer 43 veriden hareketle genel bir analiz yapıldığında ise, bengü taşlardaki paralelizm örneklerinde kagan, beg, şad, yabgu, alp, bilge, ini, eçi, kay, ogul, kız, işi yagı gibi insanla ilgili kelimelerin; ilgerü, yırıya, biriye gibi yön belirten ifadelerin; türk, tabgaç, oguz, tatabı gibi millet, boy adlarının ve bodun, il gibi terimlerin diğerlerinden daha sık kullanıldığı göze çarpmaktadır. Bu durum, Bilge Kağan, Köl Tigin ve Tonyukuk'un zihin dünyalarıyla ve siyasi konumlarıyla ilgili olsa gerektir.

Bengü taşlardaki paralelizm örneklerinin genelinde, madde başlıklarından anlaşlabileceği gibi bir tezat söz konusudur. Bazıları birbirine doğrudan zıt olmasa da bağlam içinde zıtlık oluşturabilen yablak edgü, yaz kış, kagan bodun, ogul kız, kün tün, iç taş, balık tag, türk tabgaç, kaワ ög, üze asra, teyri yir, çıgań bay, az üküş vd. tezat örneklerinin çokluğu bir dilin edebîliğini belirleyen ölçütler arasında sayılabileceği gibi, aynı zamanda dilde ustalığın da göstergesidir. Paralelizm örneklerinin bulunması ya da tezat gibi edebî sanatların örneklerinin yer alması bengü taşların manzum yazıldığını iddia etmeye yetmeyeceği gibi, aynı durumların manilerde ve atasözlerinde de bulunduğunu hatıra getirmekte ve bengü taşların dilinin buna uygun bir üslupla kaleme alındığını düşündürtmektedir.

Bengü taşların edebî değerini göstermesi ve Türk dilinin yaşı ve gelişimi konusunda önemli ipuçları veren bu tür çalışmalar arttıkça, artzamanlı ve eşzamanlı kıyaslamalar yapılabilecek, böylece de bir eserin, yazarın ya da dönemin üslubunu belirlemede güçlü analizler ortaya konabilecektir. Bundan sonra yapılması gereken ödevlerimizden biri bengü taşlardan edinilen bu verileri Eski Uygur ve Karahanlı eserleriyle karşılaştırmak ve bu karşlaştırmalar üzerinden analizler yapmak olacaktır.

\section{Kaynaklar}

Aslan, Ü. (2010). Bâbur Divanında Öncelemeler ve Öncelemelerde Paralelizm. Divan Edebiyatı Araştırmaları Dergisi, 4: 1-26.

Bayat, F. (2004). Sözlü Kültür Bağlamında Eski Türk Yazıtları. Millî Folklor, 8 (61): 13-20.

Bayat, F. (2006). Irk Bitig Metninin Poetik Yapısı. Hacettepe Üniversitesi Türkiyat Araştırmaları ergisi, 4: 39-65.

BSTS/E Oğuzkan, F. (1974). Eğitim Terimleri Sözlügü̈. Ankara: Türk Dil Kurumu Yayınları. / Bilim ve Sanat Terimleri Sözlügü (http://tdk.gov.tr/index.php?option=com_bilimsanat\&view= bilimsanat, E.T.: 30.03.2018)

BSTS/H Acıpayamlı, O. (1978). Halkbilim Terimleri Sözlüğü. Ankara: Türk Dil Kurumu Yayınları. / Bilim ve Sanat Terimleri Sözlüğ̈̈ (http://tdk.gov.tr/index.php?option=com_bilimsanat\&view =bilimsanat, E.T.: 30.03.2018) 
Dilçin, C. (1991). Fuzûlie`nin Bir Gazelinin Şerhi ve Yapısal Yönden İncelenmesi. Türkoloji Dergisi, IX/1: 43-98.

Dilçin, C. (2000). Divan Şiirindeki Paralel ve Ortak Söz Yapılarından Metin Eleştirisinde Yararlanma. Türkoloji Dergisi, XIII/1: 33-66.

GTS Güncel Türkçe Sözlük, http://tdk.gov.tr/index.php?option=com_gts\&view=gts, (E.T.: 11.05.2018)

Macit, M. (1996). Divân Şïirinde Ahenk Unsurları. Ankara: Akçağ Yayınları.

Musaoğlu, M. (2003). Türk Folklorik Metinlerinin Ontolojik-Folklorik Temelleri. Dil Dergisi, 118 ( Ocak-Şubat): 16-25.

Tekin, T. (1986). İslâm Öncesi Türk Şiiri. Türk Dili, Türk Şüiri Özel Sayısı I (Eski Türk Şïri), 409 (Ocak): 3-42. 